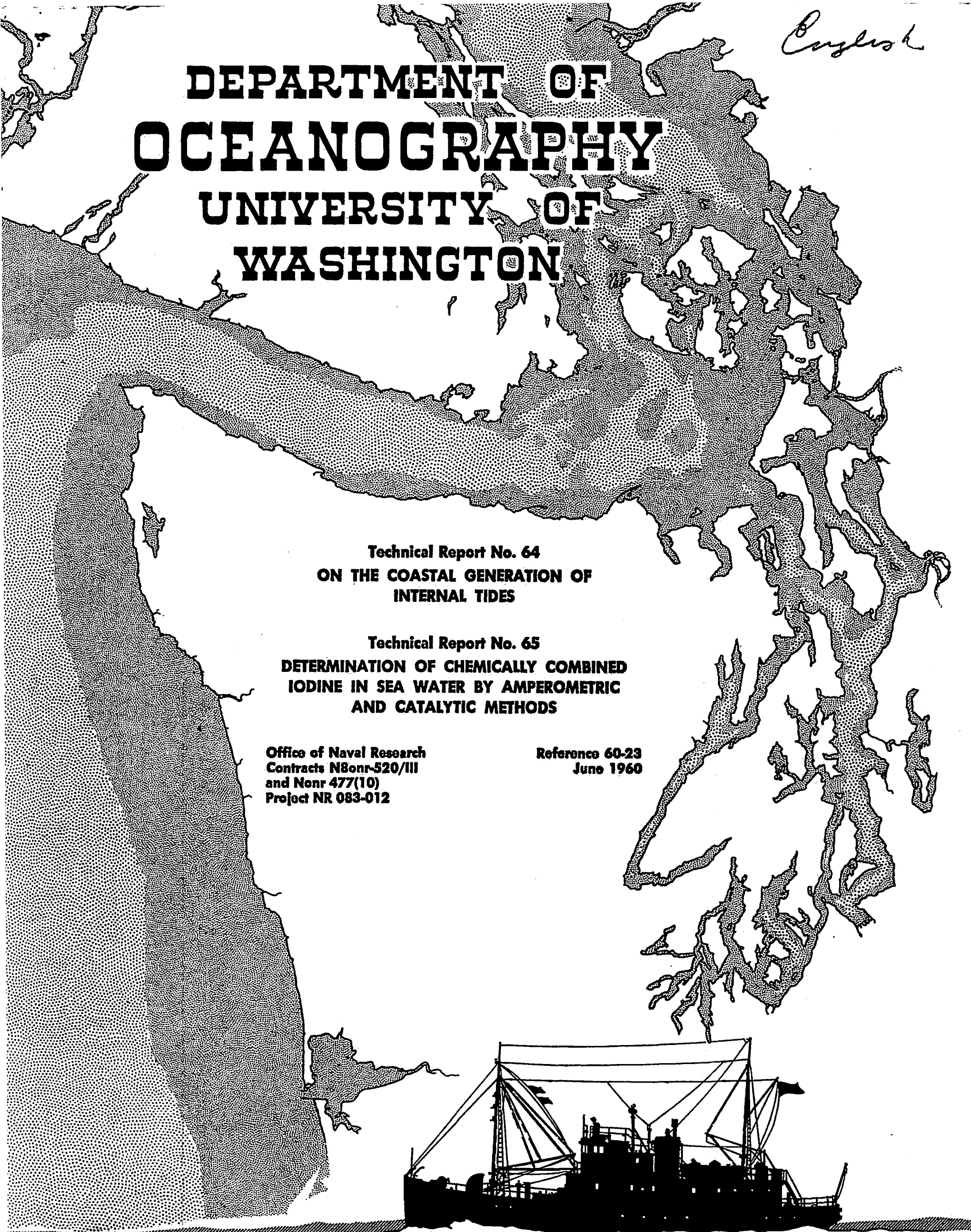


UNIVERSITY OF WASHINGTON
DEPARTMENT OF OCEANOGRAPHY
Seattle 5, Washington

Technical Report No. 64

ON THE COASTAL GENERATION OF INTERNAL TIDES

by

Maurice Rattray, Jr.

Technical Report No. 65

DETERMINATION OF CHEMICALIY COMBINED IODINE IN SEA WATER

BY AMPEROMETRIC AND CATALYTIC METHODS

by

Richard A. Barkley and Thomas G. Thompson

Office of Naval Research

Contracts N8onr $-520 /$ III

Reference 60-23

and Nonr 477(10)

Project NR 083-012

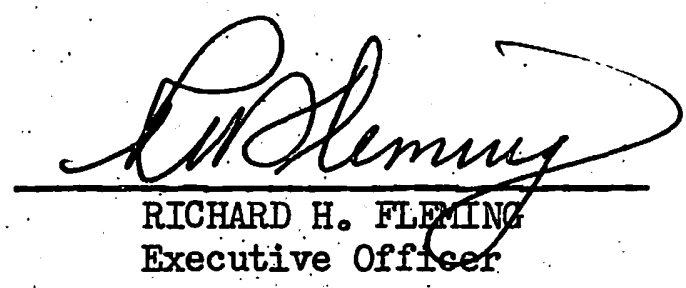

Reproduction in whole or in part is permitted for any purpose of the United States Government. 


\title{
On the Coastal Generation of Internal Tides ${ }^{1}$
}

\author{
by MAURICE RATTRAY, Jr. \\ University of Washington, Department of Oceanography, Seattle \\ (Manuscript received June 8, 1957, revised version April 15, 1959)
}

\begin{abstract}
Differential equations, boundary, and discontinuity conditions arc obtained which relate the internal tide to the surface tide in a two-layer system. Solutions of these equations give internal tides which may be large compared to the surface tide. In the coastal region these internal tides are standing waves and further offshore they attain the characteristics of progressive waves traveling seaward.
\end{abstract}

\section{Introduction}

Although internal waves of tidal period have been observed in various regions of the oceans, their distribution and manner of generation have remained largely unknown. No suitable theory has been developed as a guide to an adequate observational program or with which the results of such a program can be compared. Such a theory should eventually permit prediction of the range and phase of the internal tide from a knowledge of the important oceanographic variables.

Recently, Davis and Patrerson (1956) have summarized our knowledge on the creation and propagation of internal waves. In the majority of cases where current measurements were obtained simultaneously with observations of the vertical displacements, the internal tides were progressive waves, although in certain instances they had the nature of standing waves. Present evidence, as suggested by RudNICK and Cochrane (I95I), RATtray (I954, I957 a), and ReID (I956), points to coastal generation of the internal tides. However, although Proudman (1953) has shown under similar conditions that an ordinary tide wave, on passing over a high submarine barrier will give rise to an internal wave the actual mechanism of coastal generation has not yet been demonstrated.

In order to explain the observed internal tides, it is proposed here to investigate how they might possibly be generated in coastal regions and to determine the characteristics of the resulting waves.

\section{Nature of internal tides generated in coastal regions}

The generation of internal tides in coastal regions depends on a coupling between the surface tide and the internal tide, due primarily to marked variations in depth but also influenced by the local distribution of oceanographic propertics. Although the variations of range and time of tide along the coast have been shown to have an important influence on the longshore component of the tidal current (RATTRAY, I957 b), the wave length of the internal tide is sufficiently short compared to that of the surface tide for these variations in

\footnotetext{
1 Contribution No. 232 of the Depart nent of Oceanography, University of Washington.
} 
most cases to have only a small effect on the internal tide. Therefore, where the depth contours are reasonably parallel to the coastline, the crests of the internal waves will also be approximately parallel to the coastline.

In the coastal region, these internal tides will behave as a standing wave because of the proximity of the coast, but further offshore their nature will change to that of a progressive wave traveling seaward. In traveling offshore these progressive waves will lose their energy from friction and finally will become undetectable. While their rate of dissipation will depend on the particular oceanographic conditions (RATTRAY, I954, I957 a), the waves in most cases will be found to retain an appreciable amplitude for considerable distances from their source, but will be damped out before they impinge on another coastline. Thus, energy is continually removed from the coastal region by the progressive internal waves and, for steady state conditions, this energy must be supplied at the same rate by the coupling between the internal and surface tides. Considerations of resonance, then, are not applicable to this problem. For maximum internal tides in the ocean, maximum energy must be supplied to the internal motion by the surface tides.

The amplitude of the resulting internal tide will depend on the actual coupling mechanism between the two tides and on the amplitude of the surface tide. If the coupling remains constant, the amplitude of the internal tide in any region will be proportional to the amplitude of the surface tide along the adjacent coastline. However, the coupling can also change with a change in oceanographic conditions in the region. In order to determine this coupling it is necessary to know the occanographic conditions in the coastal and offshore regions.

The general nature of internal tides here outlined explains many of their observed features. However, the question still remains whether a coupling mechanism can be shown which will yield internal waves of the observed magnitudes. This problem will now be investigated.

\section{Derivation of the wave equation}

Consideration will be restricted to a twolayer system in which properties have no Tellus XII (1960), 1 variation in a direction parallel to the coastline and in which the difference in density between the two layers is very small compared to the density of the water in either layer, i.e. $\frac{\Delta \varrho}{\varrho} \ll$ r. The effects of friction and vertical acceleration will be assumed to be negligible. Then the equations of motion for the upper layer are:

$$
\begin{gathered}
\frac{\partial u^{\prime}}{\partial t}-2 \omega v^{\prime}=-g \frac{\partial \zeta^{\prime}}{\partial x}, \\
\frac{\partial v^{\prime}}{\partial t}+2 \omega u^{\prime}=0
\end{gathered}
$$

and the lower layer are:

$$
\begin{aligned}
\frac{\partial u^{\prime \prime}}{\partial t}-2 \omega v^{\prime \prime}= & -g\left(\mathrm{I}-\frac{\Delta \varrho}{\varrho}\right) \frac{\partial \zeta^{\prime}}{\partial x}-g \frac{\Delta \varrho}{\varrho} \frac{\partial \zeta^{\prime \prime}}{\partial x}, \\
& \frac{\partial v^{\prime \prime}}{\partial t}+2 \omega u^{\prime \prime}=0 .
\end{aligned}
$$

The equation of continuity is

$$
\frac{\partial}{\partial x}\left(h^{\prime} u^{\prime}\right)=\frac{\partial \zeta^{\prime \prime}}{\partial t}-\frac{\partial \zeta^{\prime}}{\partial t}
$$

for the upper layer, and

$$
\frac{\partial}{\partial x}\left(h^{\prime \prime} u^{\prime \prime}\right)=-\frac{\partial \zeta^{\prime \prime}}{\partial t}
$$

for the lower layer.

Here a primed quantity refers to the upper layer and a double-primed quantity to the lower layer where $u$ and $v$ are the horizontal components of velocity; $\omega$ is the vertical component of the earth's angular velocity of rotation; $g$ is the acceleration due to gravity; $\frac{\Delta \varrho}{\varrho}$ is the relative density difference between the two layers; $\zeta$ is the elevation of the upper surface of a layer; and $h$ is the layer depth.

With the time factor taken as $e^{i o t}$, where $\sigma=2 \pi /$ period, the equations become, after eliminating $v^{\prime}$ and $v^{\prime \prime}$ :

$$
i \sigma\left(\mathrm{I}-\frac{4 \omega^{2}}{\sigma^{2}}\right) u^{\prime}=-g \frac{d \zeta^{\prime}}{d x}
$$




$$
\begin{aligned}
i \sigma\left(\mathrm{I}-\frac{4 \omega^{2}}{\sigma^{2}}\right) u^{\prime \prime} & =-g\left(\mathrm{I}-\frac{\Delta \varrho}{\varrho}\right) \frac{d \zeta^{\prime}}{d x}- \\
- & -\frac{\Delta \varrho}{\varrho} \frac{d \zeta^{\prime \prime}}{d x} \\
\frac{d}{d x}\left(h^{\prime} u^{\prime}\right) & =i \sigma\left(\zeta^{\prime \prime}-\zeta^{\prime}\right) \\
\frac{d}{d x}\left(h^{\prime \prime} u^{\prime \prime}\right) & =-i \sigma \zeta^{\prime \prime}
\end{aligned}
$$

Elimination of $\zeta^{\prime \prime}, u^{\prime}$ and $u^{\prime \prime}$ results in a fourth order equation for $\zeta^{\prime}$, and setting $h=h^{\prime}+h^{\prime \prime}$ it can be written:

$$
\begin{aligned}
& {\left[\sigma^{4}\left(\mathrm{I}-\frac{4 \omega^{2}}{\sigma^{2}}\right)^{2}+\sigma^{2}\left(\mathrm{I}-\frac{4 \omega^{2}}{\sigma^{2}}\right) \frac{d}{d x}\left(g h \frac{d}{d x}\right)+\right.} \\
& \left.\quad+\frac{d}{d x}\left\{g \frac{\Delta \varrho}{\varrho} h^{\prime \prime} \frac{d^{2}}{d x^{2}}\left(g h^{\prime} \frac{d}{d x}\right)\right\}\right] \zeta^{\prime}=0 \quad \text { (I I ) }
\end{aligned}
$$

This equation has four independent solutions, two which represent surface waves and two which represent internal waves. The respective amplitudes of these waves will depend on the boundary conditions.

\section{Boundary and discontinuity conditions}

At the coastline, the $x$-component of the total transport and the transport in each layer must vanish, that is

$$
h^{\prime} u^{\prime}=h^{\prime \prime} u^{\prime \prime}=0
$$

At large distances from the coastline, where the density distribution and the total depth have become constant, the solution for the internal tide must be a progressive wave traveling seaward.

At any discontinuity (actually a change over a distance short compared to the internal wave length) of the depths or density difference, the total transport, the transport in each layer, and the pressure must be continuous. These requirements may be written:

$$
\begin{aligned}
& \delta(h u)=0, \\
& \delta\left(h^{\prime} u^{\prime}\right)=\delta\left(h^{\prime \prime} u^{\prime \prime}\right)=0, \\
& \delta \zeta^{\prime}=0, \\
& \delta\left(\Delta p \zeta^{\prime \prime}\right)=0
\end{aligned}
$$

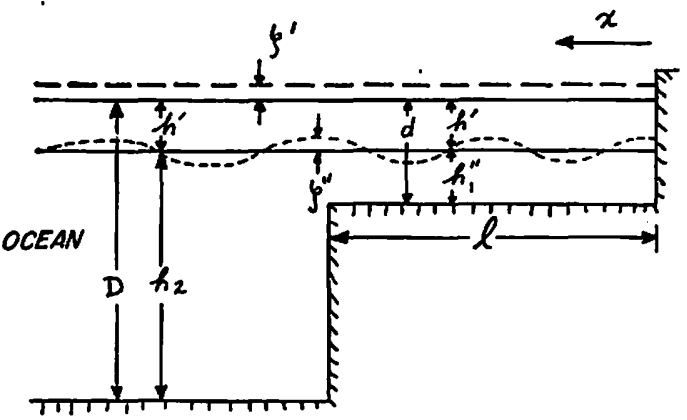

Fig. I. Model used in Example I.

where $\delta$ indicates the difference in the designated quantity on the two sides of the discontinuity.

\section{Solution for the internal tide}

When the surface tide, the bathymetry, and the internal density distribution are known over the coastal area, the resulting internal tide is obtained by solving equation (II) subject to the above conditions. A solution is always possible when the density distribution can be adequately approximated by a two-layer system. For illustration, two simple examples of exact solutions are given here to demonstrate the general nature of these internal tides.

Example 1. A model (Figure I) is taken in which the continental shelf has a uniform depth, $d$, and a width, $l$, The ocean is given a depth, $D$, and the depth of the upper layer, $h^{\prime}$, is taken to be a constant. Under these conditions the differential operator in equation (II) can be factored and the equation becomes:

$$
\begin{gathered}
{\left[\frac { \sigma ^ { 2 } } { 2 } ( \mathrm { I } - \frac { 4 w ^ { 2 } } { \sigma ^ { 2 } } ) \left(\mathrm{I}+\sqrt{\left.\mathrm{I}-\frac{4 h^{\prime} h^{\prime \prime}}{h^{2}} \frac{\Delta \varrho}{\varrho}\right)}+\right.\right.} \\
\left.+\frac{g h^{\prime} h^{\prime \prime}}{h} \frac{\Delta \varrho}{\varrho} \frac{d^{2}}{d x^{2}}\right] \cdot \\
\cdot\left[\frac { \sigma ^ { 2 } } { 2 } ( \mathrm { I } - \frac { 4 \omega ^ { 2 } } { \sigma ^ { 2 } } ) \left(\mathrm{I}-\sqrt{\left.\mathrm{I}-\frac{4 h^{\prime} h^{\prime \prime}}{h^{2}} \frac{\Delta \varrho}{\varrho}\right)}+\right.\right. \\
\left.+\frac{g h^{\prime} h^{\prime \prime}}{h} \frac{\Delta \varrho}{\varrho} \frac{d^{2}}{d x^{2}}\right] \zeta^{\prime}=0
\end{gathered}
$$

Now the solutions to these equations are:

$$
\begin{array}{ll}
\zeta^{\prime}=\zeta_{s}^{\prime}+\zeta_{i}^{\prime}, & u^{\prime}=u_{s}^{\prime}+u_{i}^{\prime} \\
\zeta^{\prime \prime}=\zeta_{s}^{\prime \prime}+\zeta_{i}^{\prime \prime}, & u^{\prime \prime}=u_{s}^{\prime \prime}+u_{i}^{\prime \prime}
\end{array}
$$


where for example $\zeta_{s}^{\prime}$ and $\zeta_{i}^{\prime}$, respectively, represent the contributions of the surface wave and internal wave to the surface elevation and where they satisfy the differential equations:

$$
\begin{gathered}
{\left[\frac{\sigma^{2}}{2}\left(\mathrm{I}-\frac{4 \omega^{2}}{\sigma^{2}}\right)\left(\mathrm{I}-\sqrt{\mathrm{I}-\frac{4 h^{\prime} h^{\prime \prime}}{h^{2}} \frac{\Delta \varrho}{\varrho}}\right)+\right.} \\
\left.+\frac{g h^{\prime} h^{\prime \prime}}{h} \frac{\Delta \varrho}{\varrho} \frac{d^{2}}{d x^{2}}\right] \zeta_{s}^{\prime}=0
\end{gathered}
$$

and

$$
\begin{gathered}
{\left[\frac { \sigma ^ { 2 } } { 2 } \left(\mathrm{I}-\frac{4 \omega^{2}}{\sigma^{2}}\left(\mathrm{I}+\sqrt{\left.\mathrm{I}-\frac{4 h^{\prime} h^{\prime \prime}}{h^{2}} \frac{\Delta \varrho}{\varrho}\right)}+\right.\right.\right.} \\
\left.+\frac{g h^{\prime} h^{\prime \prime}}{h} \frac{\Delta \varrho}{\varrho} \frac{d^{2}}{d x^{1}}\right] \zeta_{i}^{\prime}=0
\end{gathered}
$$

Since $\frac{\Delta \varrho}{\varrho} \ll I$ these equations can be approximated by only retaining terms in the lowest power of $\frac{\Delta \varrho}{\varrho}$. Then

$$
\begin{gathered}
{\left[\left(\sigma^{2}-4 \omega^{2}\right)+g h \frac{d^{2}}{d x^{2}}\right] \zeta_{s}^{\prime}=0} \\
{\left[\left(\sigma^{2}-4 \omega^{2}\right)+\frac{g h^{\prime} h^{\prime \prime}}{h} \frac{\Delta p}{p} \frac{d^{2}}{d x^{2}}\right] \zeta_{i}^{\prime}=0}
\end{gathered}
$$

and solutions to equations (7), (8), (9), (10), (2I), and (22) which satisfy boundary conditions of equations (12), (I3), and (I5) and are valid within a distance of the coast small compared to the wavelength of the surface wave are:

$\zeta_{s}^{\prime}=\zeta_{0}^{\prime}$, a constant for any $x$ small compared to wavelength of surface tide. (23)

$$
\begin{gathered}
\zeta_{s}^{\prime}=\frac{h^{\prime} \zeta_{0}^{\prime}}{d}, \text { for }-0 \leqslant x \leqslant l \\
u_{s}^{\prime}=u_{s}^{\prime \prime}=-\frac{i \sigma \zeta_{0}^{\prime} x}{d}, \text { for } 0 \leqslant x \leqslant l \\
\zeta_{s}^{\prime \prime}=\frac{h^{\prime} \zeta_{0}^{\prime}}{D}, \text { for } x \geqslant l \\
u_{s}^{\prime}=u_{s}^{\prime \prime}=-\frac{i \sigma \zeta_{0}^{\prime} x}{D}, \text { for } x \geqslant l
\end{gathered}
$$

Tellus XII (1960), 1

$$
\begin{gathered}
\zeta_{i}^{\prime \prime}=A \cos k_{1} x \text {, for } 0 \leqslant x \leqslant l \quad(28) \\
h^{\prime} u_{i}^{\prime}=\left(d-h^{\prime}\right) u_{i}^{\prime \prime}=\frac{i \sigma}{k_{1}} A \sin k_{1} x, \text { for } 0 \leqslant x \leqslant l \\
\zeta_{i}^{\prime \prime}=B e^{-i k_{x} x}, \text { for } x \geqslant l \quad(29) \\
-\left(D-h^{\prime}\right) u_{i}^{\prime \prime}=h^{\prime} u_{i}^{\prime}=-\frac{\sigma}{k_{2}} B e^{-i k_{x} x}, \text { for } x \geqslant l \\
\text { where } k_{1}^{2}=\frac{\left(\sigma^{2}-4 \omega^{2}\right) \frac{d}{h^{\prime}\left(d-h^{\prime}\right)}}{g \frac{\Delta \varrho}{\varrho}} \quad(32) \\
\text { and } k_{2}^{2}=\frac{\left(\sigma^{2}-4 \omega^{2}\right) \frac{D}{h^{\prime}\left(D-h^{\prime}\right)}}{g \frac{\Delta \varrho}{\varrho}}
\end{gathered}
$$

In the case under consideration $\zeta_{i}^{\prime} \ll \zeta_{0}^{\prime}$ and the elevation of the free surface will be taken to be that due to the surface tide. However $\frac{d \zeta_{i}^{\prime}}{d x}$ cannot be neglected. Where $h^{\prime} \geqslant d$ the above results are modified by omitting equation (I6) and substituting $d$ for $h^{\prime}$ and setting $A=0$ in the final results. Finally, the solutions of equations (I4) and (I6) for the wave amplitudes are:

$$
\begin{gathered}
A=\zeta_{0}^{\prime} h^{\prime}\left(\frac{I}{d}-\right. \\
-\frac{I}{D} \sqrt{\frac{\left(I+k_{2}^{2}(2)\right.}{\left(\cos ^{2} k_{1} l+\frac{k_{2}^{2}}{k_{1}^{2}} \sin ^{2} k_{1} l\right)}} e^{i(\alpha-\beta),}
\end{gathered}
$$

and

$$
\begin{gathered}
B=\zeta_{0}^{\prime} h^{\prime}\left(\frac{I}{d}-\right. \\
\left.\frac{\mathrm{I}}{D}\right) \frac{\left(k_{2} l \cos k_{1} l-\frac{k_{2}}{k_{1}} \sin k_{1} l\right)}{\sqrt{\left(\cos ^{2} k_{1} l+\frac{k_{2}^{2}}{k_{1}^{2}} \sin k_{1} l\right)}} e^{i\left(k_{2} l-\beta+\frac{\pi}{2}\right)},
\end{gathered}
$$




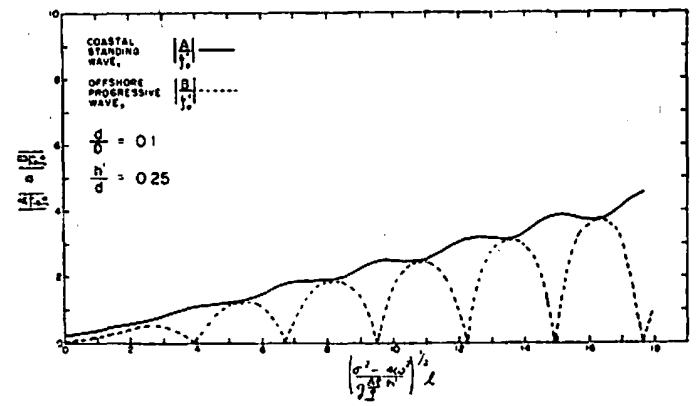

A

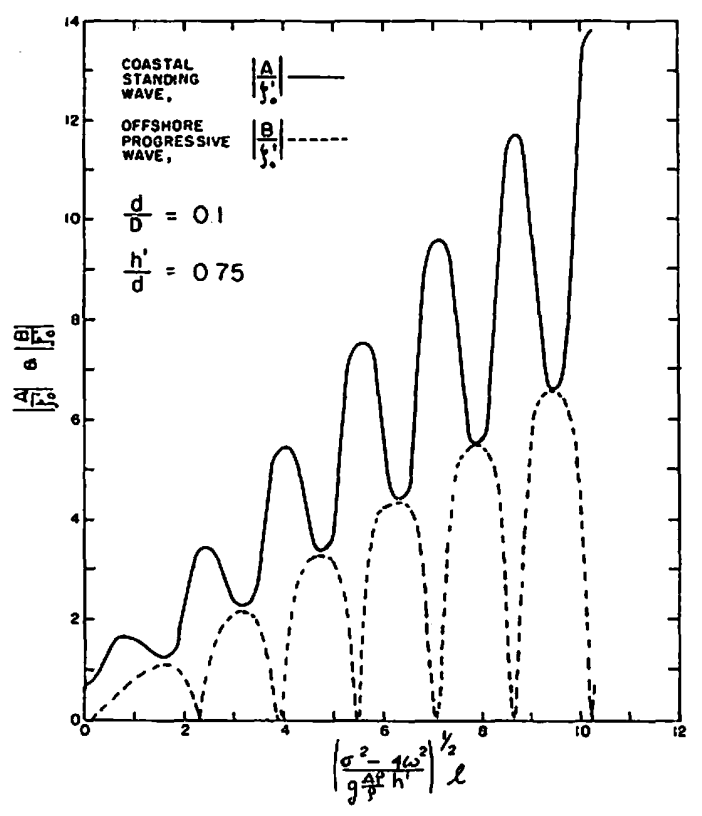

$\mathrm{C}$

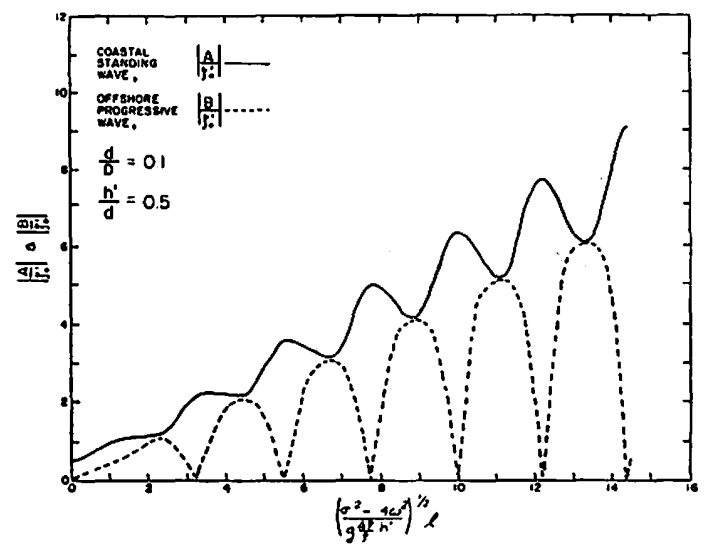

B

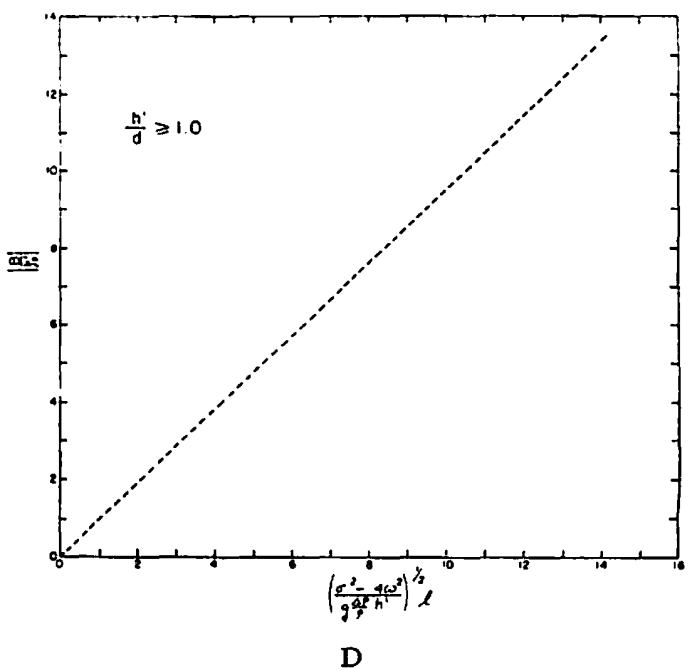

Fig. 2. (A-D): Ratio of internal to surface tidal amplitudes for some cases of Example I.

where

$$
\tan \alpha=k_{2} l \text {, }
$$

and

$$
\tan \beta=\frac{k_{2}}{k_{1}} \tan k_{1} l
$$

Figure 2 shows the ratio of internal tide amplitude to surface tide amplitude over a range of typical conditions.

Several conclusions regarding the amplitudes of the internal tides are immediately evident; they are proportional to the amplitude of the surface tide, $\zeta_{0}^{\circ}$; the depth of the surface layer, $h^{\prime} ;$ and the factor $\left(\frac{\mathrm{I}}{d}-\frac{\mathrm{I}}{D}\right)$ which represents the effect of the change in the total depth. It is interesting to note that this result implies preferential generation of waves at the greater depths. Since values of $h^{\prime}\left(\frac{\mathrm{I}}{d}-\frac{\mathrm{I}}{D}\right)$ will range between zero and one, a typical value can be taken as one-half. The generation of internal tides, large in amplitude compared to the surface tide, will depend therefore on 
the remaining factor being large compared to unity. This in turn requires $k_{2} l \gg \mathrm{I}$ and then the approximate range of values of this factor in equation (34) will lie between $k_{1} l$ and $k_{2} l$ depending on the actual phase $k_{1} l$. Thus, if large internal waves are to be generated, the approximate ratio of standing internalwave amplitude to surface-tide amplitude lies in the range,

$$
\begin{gathered}
\sqrt{\frac{\left(\sigma^{2}-4 \omega^{2}\right) \frac{D}{h^{\prime}\left(D-h^{\prime}\right)}}{g \frac{\Delta \varrho}{\varrho}} l}|<| \frac{A}{\zeta_{0}^{\prime} h^{\prime}\left(\frac{\mathrm{I}}{d}-\frac{\mathrm{I}}{D}\right.} \mid \\
<\sqrt{\frac{\left(\sigma^{2}-4 \omega^{2}\right) \frac{d}{h^{\prime}\left(d-h^{\prime}\right)}}{g \frac{\Delta \varrho}{\varrho}}} l, \quad(38)
\end{gathered}
$$

which requires that the continental shelf have a width of at least several internal wave lengths. Broad continental shelves will have, therefore, a high probability for the generation of sizeable internal tides. As might be expected from simple considerations of energy, the generation of large internal tides is favored by a relatively small difference in density between the upper and lower layers. A particularly interesting result is that the "resonance" condition $\sigma^{2} \approx 4 \omega^{2}$ (Defant, I950; Haurwitz, 1950) is unfavorable for the generation of internal waves by this mechanism.

Under the above conditions, the value for the amplitude of the seaward progressive waves is

$$
\begin{aligned}
& \left|\frac{B}{\zeta_{0}^{\prime} h\left(\frac{\mathrm{I}}{d}-\frac{\mathrm{I}}{D}\right)}\right| \approx \\
& \approx \sqrt{\frac{\left(\sigma^{2}-4 \omega^{2}\right) \frac{D}{h^{\prime}\left(D-h^{\prime}\right)}}{g \frac{\Delta \varrho}{\varrho}} l \cos k_{1} l .}
\end{aligned}
$$

The general statements above thus pertain also to the magnitude of these progressive waves. However, there is an additional factor, $\cos k_{1} l$, which will range from zero to one depending on the value of $k_{1} l$. It is possible, Tellus XII (1960). 1

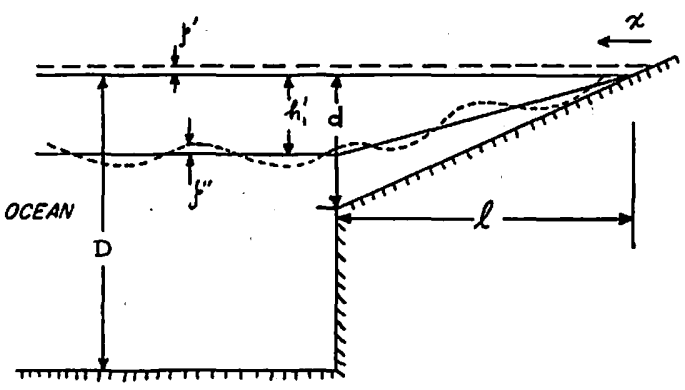

Fig. 3. Model used in Example 2.

then, to have large internal tides in the immediate coastal region and yet have no appreciable evidence of such motion in the teeper water. In no case will the progressive wave amplitude exceed that of the standing wave. Also under the conditions most suitable for the generation of large internal waves, $k_{1} l$ can undergo sizeable fluctuations with small changes in water characteristics. On a statistical basis, the amplitudes of the progressive waves would be expected to be greater than onehalf those of the standing waves for twothirds of the observations.

Example 2. A model (Figurc 3) in which the depth of the shelf increases linearly with distance offshore is more realistic in many cases and can be obtained by setting

$$
h=\left(h^{\prime}+h^{\prime \prime}\right)=\frac{x d}{l}, \quad \text { for } 0 \leqslant x \leqslant l .
$$

Then, in order that equation (II) may be solved in a simple fashion, the depth of the upper layer is taken to be

$$
h^{\prime}=\frac{h_{1}^{\prime} x}{l}, \quad \text { for } 0 \leqslant x \leqslant l .
$$

This corresponds to a case where a longshore current exists in balance with this slope. Since it is normal to find longshore currents at coastal boundaries, this example is more realistic than the previous one. For $x \geqslant l$, the conditions are taken to be the same as for Example I and then cquations (2I) and (22) will apply to this region. For $0 \leqslant x \leqslant l$, equation (II) will become 


$$
\begin{gathered}
\left\{\sigma^{2}\left(\mathrm{I}-\frac{4 \omega^{2}}{\sigma^{2}}\right)\left(\frac{\mathrm{I}+\sqrt{\mathrm{I}-\frac{4 h_{1}^{\prime}\left(d-h_{1}^{\prime}\right)}{d^{2}} \frac{\Delta \varrho}{\varrho}}}{2}\right)+\right. \\
\left.+\frac{d}{d x}\left(g \frac{h_{1}^{\prime}\left(d-h_{1}^{\prime}\right)}{d} \frac{\Delta \varrho}{\varrho} \frac{x}{l} \frac{d}{d x}\right)\right\} \\
\cdot\left\{\sigma^{2}\left(\mathrm{I}-\frac{4 \omega^{2}}{\sigma^{2}}\right)\left(\frac{\mathrm{I}-\sqrt{\mathrm{I}-\frac{4 h_{1}^{\prime}\left(d-h_{1}^{\prime}\right)}{d^{2}} \frac{\Delta \varrho}{\varrho}}}{2 \frac{h_{1}^{\prime}\left(d-h_{1}^{\prime}\right)}{d^{2}} \frac{\Delta \varrho}{\varrho}}\right)+\right. \\
\left.+\frac{d}{d x}\left(g d \frac{x}{l} \frac{d}{d x}\right)\right\} \zeta^{\prime}=0
\end{gathered}
$$

Again setting $\zeta^{\prime}=\zeta_{s}^{\prime}+\zeta_{i}^{\prime}$ and approximating by neglecting higher powers of $\frac{\Delta \varrho}{\varrho}$, equation (42) is split into the two equations:

$$
\left[\left(\sigma^{2}-4 \omega^{2}\right)+g d \frac{d}{d x}\left(\frac{x}{l} \frac{d}{d x}\right)\right] \zeta_{s}^{\prime}=0,
$$

and

$$
\left[\left(\sigma^{2}-4 \omega^{2}\right)+g h_{1}^{\prime}\left(\mathrm{I}-\frac{h_{1}^{\prime}}{d}\right) \frac{\Delta \varrho}{\varrho} \frac{d}{d x}\left(\frac{x}{l} \frac{d}{d x}\right)\right] \zeta_{i}^{\prime}=0 \text {. }
$$

The solutions of differential equations (7), (8), (9), (10), (2I), (22), (43), and (44) subject to the boundary conditions of equations (I2), (13), and (IS) are:

$\zeta_{s}^{\prime}=\zeta_{0}^{\prime}$, a constant for any $x$ small compared to wavelength of surface tide

$$
\zeta_{s}^{\prime \prime}=\frac{h_{1}^{\prime} \zeta_{0}^{\prime}}{d}, \text { for } 0 \leqslant x \leqslant l
$$

$$
u_{s}^{\prime}=u_{s}^{\prime \prime}=-\frac{i \sigma \zeta_{0}^{\prime} l}{d}, \text { for } 0 \leqslant x \leqslant l
$$

$$
\zeta_{s}^{\prime \prime}=\frac{h_{1}^{\prime} \zeta_{0}^{\prime}}{D}, \text { for } x \geqslant l
$$

$$
u_{s}^{\prime}=u_{r}^{\prime \prime}=-\frac{i \sigma \zeta_{0}^{\prime} x}{D}, \text { for } x \geqslant l
$$

$$
\zeta_{i}^{\prime \prime}=A J_{0}\left(2 k_{1} l^{1 / 2} x^{1 / 2}\right) \text {, for } 0 \leqslant x \leqslant l
$$

$$
h_{1}^{\prime} u_{i}^{\prime}=-\left(d-h_{1}^{\prime}\right) u_{i}^{\prime \prime}=\frac{i \sigma}{k_{1}} A \frac{l^{1 / 2}}{x^{1 / 2}} J_{1}\left(2 k_{1} l^{1 / 2} x^{1 / 2}\right) \text {, }
$$

$$
\text { for } 0 \leqslant x \leqslant l
$$

$$
\begin{gathered}
\zeta_{i}^{\prime \prime}=B e^{-i k_{2} x} \text {, for } x \geqslant l \quad(s 2) \\
-\left(D-h_{1}^{\prime}\right) u_{i}^{\prime \prime}=h_{1}^{\prime} u_{i}^{\prime}=-\frac{\sigma}{k_{2}} B e^{-i k_{2} x}, \text { for } x \geqslant l \\
\text { where } k_{1}^{2}=\frac{\left(\sigma^{2}-4 \omega^{2}\right) \frac{d}{h_{1}^{\prime}\left(d-h_{1}^{\prime}\right)}}{g \frac{\Delta \varrho}{\varrho}} \quad(s 4) \\
\text { and } k_{2}^{2}=\frac{\left(\sigma^{2}-4 \omega^{2}\right) \frac{D}{h_{1}^{\prime}\left(D-h_{1}^{\prime}\right)}}{g \frac{\Delta \varrho}{\varrho}}
\end{gathered}
$$

Again as in Example $\mathrm{r}, \zeta_{i}^{\prime}$ has been neglected compared to $\zeta_{0}^{\prime}$. Where $h_{1}^{\prime} \geqslant d$ the above results are modified by omitting equation (I6), and substituting $d$ for $h_{1}^{\prime}$, setting $A=0$ in the final results. Application of equations (I4) and (16) give solutions for the wave amplitudes, analogous to equations (34) and (35) which are

$$
\begin{array}{r}
A=\zeta_{0}^{\prime} h_{1}^{\prime}\left(\frac{I}{d}-\frac{I}{D}\right) \sqrt{\frac{I+k_{2}^{2} l^{2}}{\frac{}{\left[J_{0}\left(2 k_{1} l\right)\right]^{2}+\frac{k_{2}^{2}}{k_{1}^{2}}\left[J_{1}\left(2 k_{1} l\right)\right]^{2}}}} \\
e^{i(\alpha-\nu),} \quad(s \sigma)
\end{array}
$$

and

$$
\begin{aligned}
B=\zeta_{0}^{\prime} h_{1}^{\prime}\left(\frac{\mathrm{I}}{d}-\frac{\mathrm{I}}{D}\right) \frac{\left\{k_{2} l J_{0}\left(2 k_{1} l\right)-\frac{k_{2}}{k_{1}} J_{1}\left(2 k_{1} l\right)\right\}}{\sqrt{\left[J_{0}\left(2 k_{1} l\right)\right]^{2}+\frac{k_{2}}{k_{1}}\left[J_{1}\left(2 k_{1} l\right)\right]^{2}}} \\
e^{i\left(k_{1} l-v+\frac{\pi}{2}\right)}
\end{aligned}
$$

where

$$
\tan \nu=\frac{k_{2} J_{1}\left(2 k_{1} l\right)}{k_{1} J_{0}\left(2 k_{1} l\right)}
$$

Figure 4 shows the ratio of internal tide amplitude to surface tide amplitude over a range of typical conditions. The general remarks made for Example I also apply to this case. The only significant difference occurs in the standing wave, which here increases in amplitude and decreases in wave length towards the coast. For numerical illustration, 


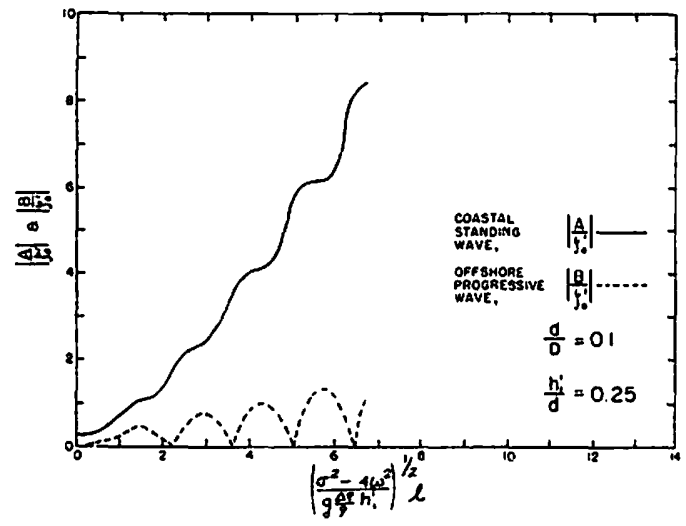

A

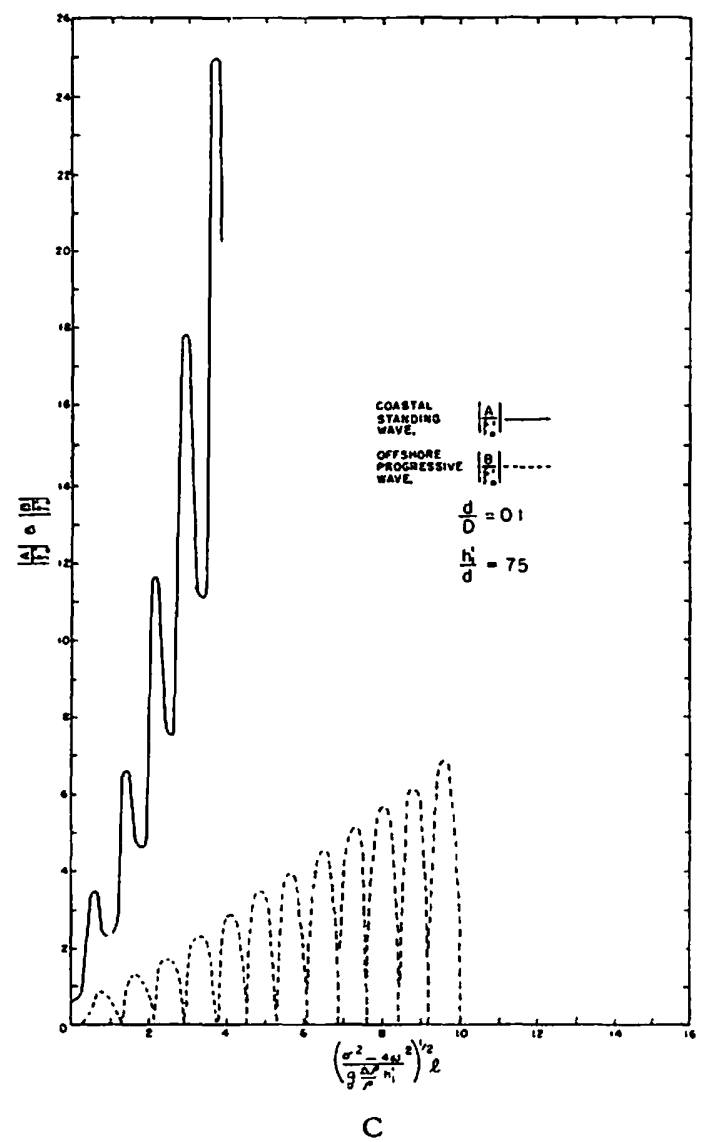

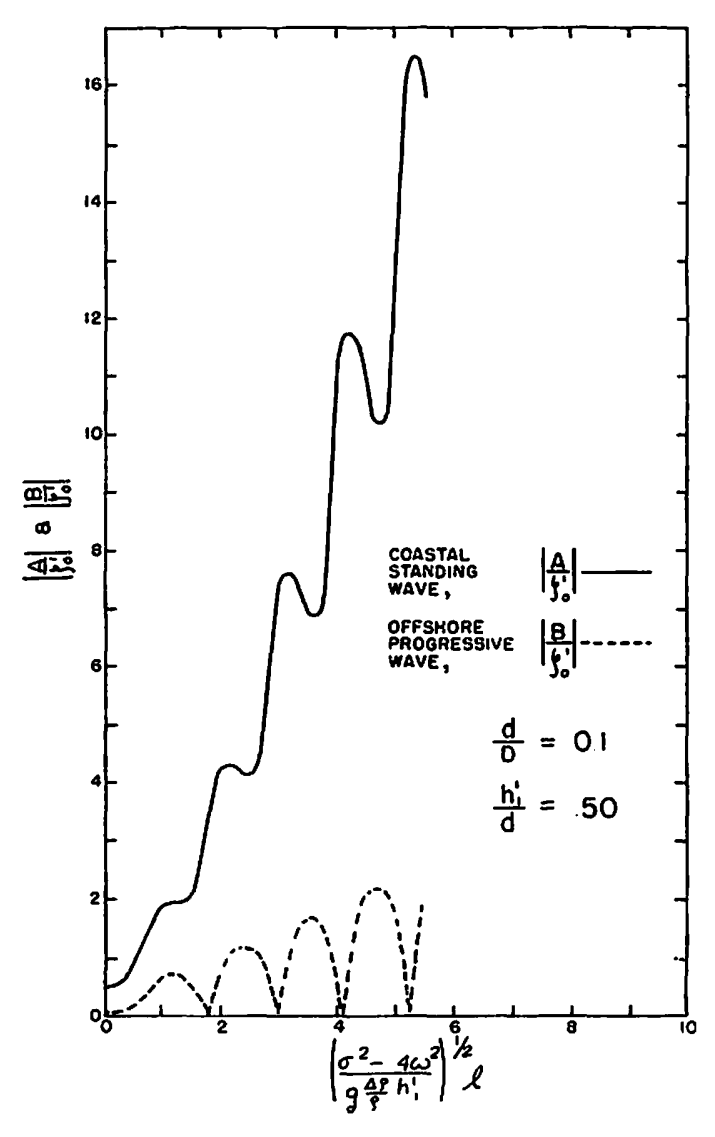

B

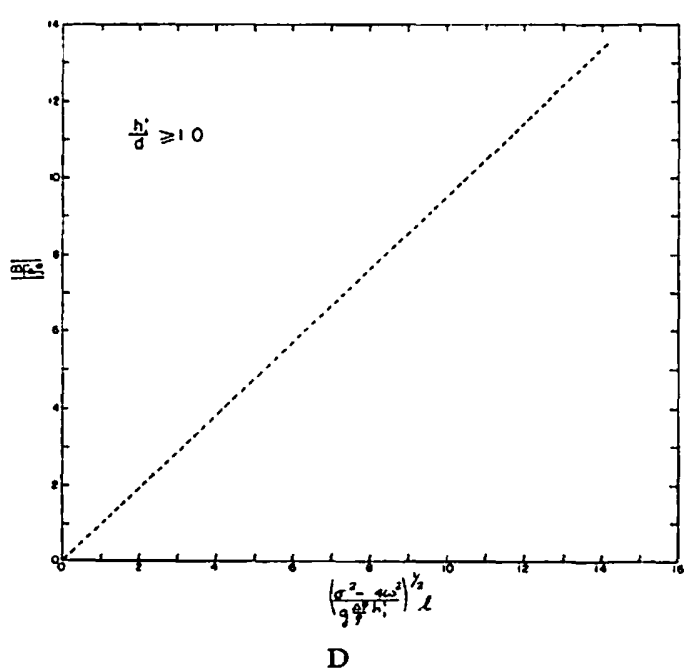

Fig. 4. (A-D): Ratio of internal to surface tidal amplitudes for some cases of Example 2.

Tellus XII (1960), 1 
consider the following conditions, typical of the Washington coast:

$$
\begin{aligned}
h_{1}^{\prime} & =100 \mathrm{~m}, \\
d & =200 \mathrm{~m}, \\
D & =1,000 \mathrm{~m} \\
\frac{\Delta \varrho}{\varrho} & =10^{-3} \\
l & =65 \mathrm{~m} \\
\text { latitude } & =47^{\circ} \mathrm{N} \\
\text { period } & =12 \mathrm{hrs} \\
\text { tidal range, } 2 \zeta_{0}^{\prime} & =2 \mathrm{~m} .
\end{aligned}
$$

Then the calculated range of the internal tide is $5.6 \mathrm{~m}$ in deep water and at the edge of the continental shelf. A small change in inshore conditions could increase this range to $7.8 \mathrm{~m}$. According to the theory it would become $46 \mathrm{~m}$ at the coastline. Evidently the approximations here used are violated in the shallower water but there is no doubt that these large waves would have a profound effect on the oceanographic conditions in this region.

\section{Summary and conclusions}

Possible generation of appreciable internal tides by the surface tides has been shown in rcgions where the depth has markcd variations with horizontal position. These internal tides behave like standing waves in the coastal region but further offshore they change to progressive waves traveling seaward. At any given location the amplitude and phase of the internal tide relative to that on the surface will depend on the particular depth and density distributions occurring in the generating region and in the area between it and the observing location.
In order to be useful in predicting internal tides, the above theory for a two-layer system must be generalized to the case of a continuous density distribution. The general features demonstrated above would still be valid but certainly the detailed motion could not be determined directly from these results. However, the validity of the postulated mechanisms for the generation of the internal tide can be determined by suitable current and hydrographic observations. This will require running a grid of stations situated over and just off the continental shelf to determine the mean density distribution in the area and then obtaining time studies at selected stations to determine the nature of the internal waves. These time studies should include measurement of the variations in the vertical distribution of properties and the horizontal currents associated with these variations. Multiple shipoperations would seem preferable in order to compare the simultancous oscillations at several locations. However, if the mean density distribution remains fixed over the time of the survey, one vessel should be ablc to obtain significant results.

To the author's knowledge, no obscrvations to this date are sufficiently detailed to show more than a general agreement with the above theory. It is hoped that future measurements on internal tides will obtain all the required data to answer this question.

\section{Acknowledgement}

This paper represents rcsults of work carried out by the Department of Oceanography of the University of Washington under Contract N8onr-520/III, Project 083-012 with the Office of Naval Research.

\section{REFERENCES}

Davis, P. A. and Ashton M. Patrerson, 1956: The creation and propagation of internal waves, a literature survey. Pac. Nav. Lab. Tech. Memo. 56-2.

Defant, Albert, 1950: On the origin of internal tide waves in the open sea. J. Mar. Res., 9, pp. I I I-I I9.

HAURwITZ, BERNARD, I950: Internal waves of tidal character. Trans. Amer. Geophys. Union.,31, pp. 47-\$2.

Proudman, J., I953: Dynamical Oceanography, Methuen \& Co. Ltd., London, pp. 349-35I.

Rattray, Maurice Jr., 1954: Propagation and dissipapation of long internal waves. Dept. Oceanogr., Univ. Wash., Tech. Rept. 27, Ref. 54-11.
Rattray, Maurice JR., 1957a: Propagation and dissipation of long internal waves. Trans. Amer. Geopliys. Union, 38, pp. 495-soo.

Rattray, Maurice Jr., I957b: On the offshore distribution of tide and tidal current. Trans Amer. Geophys. Union, 38, pp 675-680.

REID, JosEPH L., JR., 1956: Observations of internal tides in October I950. Trans. Amer. Geophys. Union, 37, pp. 278-286.

Rudnick, Philip and J. D. Cochrane, I95I: Diurnal fluctuations in bathythermograms. J. Mar. Res., I0, pp. $257-262$. 